\title{
Únete a la causa: propaganda en conflicto armado en Colombia ${ }^{*}$
}

\author{
Carlos Mario Berrío Meneses
}

Recibido: 20 de febrero de 2012 Aprobado: 27 de marzo de 2012

\begin{abstract}
Resumen
El recrudecimiento del conflicto armado en Colombia durante los años noventa obligó al Estado colombiano y especialmente a sus Fuerzas Armadas a realizar una serie de transformaciones para enfrentar las amenazas que ponían en riesgo su viabilidad. Las comunicaciones y el manejo de la información fue una de las áreas que mayores cambios sufrió, convirtiéndose hoy día en pilar fundamental de la estrategia contrainsurgente. Así, la propaganda y la guerra psicológica han sido utilizadas activamente para quebrar la voluntad de lucha de los combatientes de los grupos insurgentes, mantener la moral de los miembros de la fuerza pública y aumentar el apoyo de la población civil y la opinión pública hacia las Fuerzas Armadas.

Estas consideraciones se ponen de manifiesto en este trabajo, el cual es un avance parcial de los resultados de la investigación titulada: "Análisis comparativo de los modelos de propaganda y comunicación política entre el Socialismo del Siglo XXI y la Seguridad Democrática", la cual abarca el periodo comprendido entre 2002 y 2010.

Palabras clave: Propaganda. Operaciones psicológicas. Conflicto armado. Comunicación. Spots de televisión.
\end{abstract}

* Esta investigación fue financiada por la Vicerrectoría de Investigaciones de la Universidad de Medellín y contó con el apoyo decidido del Centro de Investigación en Comunicación y afines, de la Universidad de Medellín.

** Magíster en Estudios Políticos y Publicista de la Universidad Pontificia Bolivariana, Medellín, Colombia. Actualmente se desempeña como docente investigador y Coordinador de la Maestría en Comunicación de la Universidad de Medellín. Correo electrónico: caberrio@udem.edu.co 


\title{
Join the Cause. \\ Leitmotiv in the Armed Conflict in Colombia
}

\begin{abstract}
Reemergence of an armed conflict in Colombia during the 90's took the Colombian State, especially its Armed Forces, to perform a number of changes for fighting the threats which imperiled its functioning. Communication and information management was a field which experienced the most significant changes, since it has currently become a strategic milestone for fighting insurgency. Leitmotiv and psychological war have been actively used for breaking the rebels' fighting will, keeping morale of law enforcement entities' members, and increasing civilians and public opinion support to the Armed Forces.

These considerations have been clearly established in this article, which is a partial disclosure of results from a research entitled: "Comparative Analysis of Leitmotiv and Political Communication Models between the 21 st Century Socialism and Democratic Security," which covers a period of time between 2002 and 2010. This research was sponsored by Universidad de Medellin Research Vice-Principal's Office and totally supported by "Centro de Investigación en Comunicación y Afines" from Universidad de Medellin.
\end{abstract}

Key Words: leitmotiv; psychological operations; armed conflict; communication; TV spots. 


\section{Introducción}

Desde la perspectiva de Martin Van Creveld (1999) es posible calificar al Estado colombiano como una institución históricamente débil que ha sido incapaz de someter bajo un dominio constante a todas las regiones del territorio nacional, establecer proyectos que agrupen a la sociedad bajo su dirección, distribuir equitativamente la riqueza y los recursos, y someter efectivamente a todos los sectores de la población a través de la Administración de Justicia y coerción.

Por este motivo, el alzamiento en armas contra el Estado, que puede hacer una región, un individuo, un grupo de individuos, un partido político, etc., es en realidad una constante histórica que puede evidenciarse fácilmente en las abundantes guerras civiles del siglo XIX y en los recurrentes períodos de violencia de la última mitad del siglo XX, donde los grupos insurgentes fueron protagonistas de primer orden.

Ahora bien, es necesario poner de manifiesto que estos grupos insurgentes (salvo el M-19) nacieron en regiones apartadas de la geografía nacional donde la presencia del Estado colombiano había sido nula o, en el mejor de los casos, sumamente escasa. Por esto, dichos grupos en sus primeras décadas se convirtieron en una molestia para el Estado, pero nunca en una verdadera amenaza, puesto que nunca estuvieron en capacidad de poner en peligro la viabilidad del Estado o su control sobre zonas estratégicas.

No obstante, esta dinámica empezó a cambiar a finales de los años ochenta y se hizo más evidente en los años noventa, período en que el conflicto bélico se hizo especialmente activo y el Estado se enfrentó a nuevos escenarios, que si bien habían sido previstos desde lo teórico, en la realidad colombiana no se habían experimentado. Así, los ataques sobre la base militar de Las Delicias, las acciones de Patascoy, El Billar, Juradó, etc., se convirtieron en importantes derrotas para las
Fuerzas Militares colombianas y evidenciaron que en el caso específico de las FARC, este movimiento subversivo estaba realizando un importante salto cualitativo en su manera de enfrentar el conflicto.

Reconocidos analistas del conflicto colombiano, como Alfredo Rangel (1996) no dudaron en afirmar que las FARC se encontraban haciendo el tránsito de la guerra de guerrillas a la guerra de movimientos. Esta interpretación surge de los conceptos elaborados por Mao Tse Tung en la guerra popular prolongada, donde la primera etapa es conocida como la guerra de guerrillas, en la cual el grupo insurgente se encuentra en una fase de nacimiento y por lo tanto sus recursos y conocimiento bélico son escasos. Esto obliga al grupo insurgente a rehuir la lucha frontal contra el Estado y sus fuerzas militares y solo atacarlo en los puntos donde es extremadamente débil. Por otra parte, la guerra de movimientos representa el segundo paso en este tipo de lucha y se inicia cuando se interpreta que se ha ganado la primera etapa. En este punto el grupo subversivo tiene una cantidad de recursos mucho mayor y su capacidad bélica se ha incrementado notablemente; en este caso, el grupo puede hacer importantes movimientos de tropas y recursos, y enfrentarse abiertamente a las fuerzas del Estado. Esta etapa es la antesala de una última fase que se conoce como la guerra de posiciones, donde el grupo subversivo no solo tiene la capacidad de movilizar una gran cantidad de recursos, hombres y equipo bélico, sino que es capaz de mantener el control físico de territorios específicos y defenderlos efectivamente de los intentos de recuperación que pueda emprender el Estado.

Un ejemplo de esta última etapa pudo apreciarse claramente en El Salvador en los años noventa, donde el Frente Farabundo Martí para la Liberación Nacional FMLN, fue capaz de controlar militarmente durante varios días, grandes sectores de la capital San Salvador a pesar del esfuerzo continuo por impedirlo que hacían las Fuerzas Militares salvadoreñas. Esto finalmente obligó al 
Estado a reconocer que se encontraba perdiendo la guerra y más tarde a aceptar sentarse en la mesa de negociación con el FMLN.

Aunque la situación colombiana no era igual a la salvadoreña, se evidenciaba que las FARC se movían fácilmente por el sur del país y podían atacar con éxito a casi cualquier unidad del Ejército de Colombia que operara en esa zona. Esto llevó a muchos analistas a considerar que en este país el Estado se encontraba a las puertas de ser clasificado como un Estado en vía de fracaso (Pizarro Leóngomez, 2004)

Fue en este contexto donde el Estado colombiano inició una serie de reformas para enfrentar a esta amenaza, la cual se combinaba con el narcotráfico. Dichas transformaciones que iniciaron en el interior del Ejército, luego fueron extendidas de alguna manera a la Armada y a la Fuerza Aérea, y fueron conocidas como la Reforma Militar (Patiño, Vargas, 2006). Esta fue orientada en un principio por el gobierno del presidente Andrés Pastrana, pero obtuvo toda su visibilidad e impulso en el gobierno del presidente Álvaro Uribe.

Paradójicamente, uno de los componentes que más cambios evidenció fue el de comunicaciones, convirtiéndose paulatinamente en un elemento fundamental del fortalecimiento de las fuerzas y del Estado mismo. Dicho componente tuvo que enfrentar una creciente percepción de que en el proceso de paz llevado a cabo en la zona conocida como El Caguán eran las FARC quienes se encontraban ganando la guerra, mientras el Estado debilitado exhibía un Ejército poco profesional y condenado al fracaso.

No obstante, paulatinamente esa percepción fue cambiando hasta transformarse radicalmente en la situación opuesta. En este sentido, es necesario resaltar que a finales del segundo período presidencial de Álvaro Uribe, los niveles de popularidad del mandatario eran notablemente altos, sustentados principalmente sobre la idea de que él, al mando de las Fuerzas Militares había arrinconado a la guerrilla y el país se encontraba en una situación diametralmente opuesta a la que enfrentaba el gobierno anterior.

Además, la imagen de las Fuerzas Militares y especialmente la del Ejército se encontraba en su nivel más alto, gozando de un alto nivel de credibilidad y confianza, a pesar de que muchos de sus miembros se hallaban inmiscuidos en procesos de violación de derechos humanos.

\section{Metodología}

Como se enunció anteriormente este trabajo recoge avances parciales de la investigación titulada: “Análisis comparativo de los modelos de propaganda y comunicación política entre el Socialismo del Siglo XXI y la Seguridad Democrática", la cual se desarrolló en dos etapas. En primera instancia, y siguiendo un modelo comparativo de carácter cualitativo desde la perspectiva histórica, se procedió a definir -por una parte-, cuáles son los fundamentos teóricos del socialismo del siglo XXI en Venezuela y -por otra-, cuáles eran los fundamentos de la Seguridad Democrática en Colombia.

Para abordar este tema, se realizó una exploración de dichos proyectos políticos a través de revisión documental y entrevistas con expertos en política, comunicaciones y guerra psicológica, lo que permitió reconocer que su enfoque y objetivos eran completamente diferentes.

En segunda instancia, tras conocer los aspectos fundamentales de estos proyectos, se clasificaron las campañas de propaganda blanca ${ }^{1}$ emitida por los respectivos gobiernos y luego se determinó cuáles de estas recogían de manera

1 Es necesario aclarar que el interés de abordar este tipo de propaganda e ignorar la propaganda gris y negra se debe a la imposibilidad de rastrear las fuentes de este tipo de propaganda. Esta decisión se tomó basándose en la definición de propaganda blanca, negra y gris que hacen Hernández e Infante. 
más explícita dichos conceptos. Aunque si bien, como se explicará después, la propaganda y, aún más, la guerra psicológica son acciones de comunicación que recogen discursos, uso de la información noticiosa e inclusive el vestuario y la arquitectura, entre muchas otras cosas, en este proyecto se analizaron principalmente las campañas, puesto que estas recogen los elementos más visibles de la propaganda y nos permitieron delimitar claramente la muestra.

Con base en esto, se pudo determinar que las campañas propagandísticas que en Colombia mejor recogían los preceptos de la Seguridad Democrática eran: "Los héroes en Colombia sí existen", "Vive Colombia, viaja por ella" y "La desmovilización es la salida"; mientras por otra parte, las campañas que mejor recogían los conceptos del Socialismo del Siglo XXI eran: "Que siga la revolución", "Venezuela de verdad" y finalmente, un conjunto de campañas que si bien están referenciadas bajo nombres diferentes expresan la misma idea y son ellas conocidas como: "Acuérdate de abril”, "El Caracazo" y "Nunca más será traicionada".

La elección de estas campañas se fundamentó en lo anteriormente mencionado y en que dado que el análisis fue comparativo, se buscaba que estas estuvieran orientadas a públicos similares. Así, las campañas de los Héroes sí existen, Vive Colombia, Que siga la revolución y Venezuela de verdad estaban dirigidas a la población civil, que bien dentro de las clasificaciones de la propaganda puede considerarse inicialmente como un público neutral. Por otra parte, la campaña La desmovilización es la salida, Acuérdate de abril, el caracazo y Nunca más será traicionada estaba enfocada a un público que se considera enemigo y se pretende que no lo siga siendo. Es necesario destacar que si bien en Venezuela estas campañas no están orientadas a un público que se declara abiertamente enemigo, sí hay características importantes para determinar que estas utilizan la figura de enemigo como un elemento retórico y pretenden limitar el apoyo que la población civil les brinda a estas instituciones o personajes considerados enemigos.

En última instancia, ante la incapacidad de recolectar datos de campañas en Venezuela, dirigidas a un público interno como la dirección del partido de gobierno o los funcionarios públicos que se consideran amigos, se ignoraron las campañas internas que en Colombia están dirigidas al personal de las Fuerzas Militares y de Policía, con el fin de mantener el equilibrio en las variables analizadas en uno y otro caso.

Finalmente, sobre estas campañas se realizó un análisis semiótico del mensaje, con base en las posturas de Van Djjk, y se clasificaron según el modelo de propaganda establecido por Jean Marie Domenach (1964) y que es conocido como Las leyes de la propaganda.

\section{La propaganda}

Erwin W. Fellows (1959) plantea que el significado de las palabras cambia de acuerdo con el contexto cultural donde estas son empleadas. Esto explicaría por qué resulta en extremo difícil encontrar una definición clara y precisa de la palabra Propaganda, puesto que esta ha mutado constantemente a través del tiempo. En primer lugar, este autor afirma que la palabra en cuestión fue utilizada durante el siglo XVI dentro de un contexto científico y especialmente biológico, puesto que se usó para referirse a la reproducción animal y vegetal. No obstante, fue el Papa Gregorio XIII quien le dio un nuevo significado al crear una comisión de tres cardenales encargados de propagar las doctrinas católicas, agrupados bajo el nombre de Congregatio de Propaganda fide. Desde este punto, la palabra Propaganda ha venido siendo utilizada por la Iglesia católica para denominar sus actividades persuasivas para la propagación de la fe.

La primera vez que la palabra apareció en el inglés fue en 1718, y fue utilizada en el mismo 
marco, es decir, en el contexto religioso para describir la expansión de las doctrinas religiosas por encima de la razón, situación que se conservó durante los siglos XVIII y XIX. Sin embargo, durante el siglo XX puede observarse un cambio en el contexto donde es usada la palabra, hasta centrarse en el campo político y especialmente en el militar, donde empieza a sufrir connotaciones desfavorables por ser relacionada con la mentira, la guerra y el engaño.

Desde esta perspectiva, Antony Pratkanis y Elliot Aronson escribieron su libro La era de la propaganda. Uso y abuso de la persuasión (1994), donde le atribuyen a la propaganda una connotación casi exclusivamente política y en gran medida negativa. Así, en este libro se define a la propaganda como "las técnicas de persuasión masiva que han llegado a caracterizar a nuestra sociedad posindustrial” (Pratkanis y Aronson, 1994, 66), o también: "sugestión o influencia en las masas mediante la manipulación de los símbolos y la psicología individual. La propaganda es la comunicación de un punto de vista con la finalidad última de que el destinatario de la llamada llegue a aceptar voluntariamente esta posición como si fuese la suya" (Pratkanis y Aronson, 1994, 29).

Puede apreciarse claramente que en la definición que estos dos autores plantean, la propaganda tiene una finalidad clara: provocar una respuesta por parte del receptor. Sin embargo, no se especifica en qué campos o en qué actividades debe darse una respuesta, es decir, que si el emisor propagandístico desea que sus receptores consuman cierto tipo de productos con el fin de obtener beneficios económicos, esta actividad también puede ser clasificada como propaganda.

Se evidencia entonces que el significado de la palabra propaganda no se limita a los campos religioso, político y militar, sino que también abarca el campo comercial y el económico. Esta posición es compartida por autores como Héctor Hernández y Renaldo Infante $(1991,127)$, quienes dan a entender que la propaganda también tiene una dimensión comercial.

Esta posición también es, en parte, compartida por K. Young $(1967,242)$, quien define: "La Propaganda es el uso más o menos deliberado, planeado y sistemático de símbolos, principalmente mediante la sugestión y otras técnicas psicológicas conexas, con el propósito, en primer lugar, de alterar y controlar las opiniones, ideas y valores, y en último término, de modificar la acción manifiesta según ciertas líneas predeterminadas". Ahora bien, es evidente que Young no discrimina entre dimensiones culturales, políticas, religiosas o económicas en su definición.

Por otra parte, si bien la palabra publicidad es utilizada tempranamente por Habermas en Historia y crítica de la opinión pública, para evidenciar todo lo que puede hacerse público, su significado hoy día ha variado considerablemente hasta limitarse al área comercial y especialmente al campo del mercadeo. Así, se entiende que esta es una herramienta del mercadeo y es definida como aquella comunicación persuasiva que tiene como objetivo principal obtener un lucro económico.

Al respecto, cuando esta actividad empieza a tecnificarse y obtener mayores grados de sofisticación en la segunda mitad del siglo XX, se evidencia una clara motivación por separar a la publicidad de la propaganda. Dicho interés tiene sus orígenes en la negativa imagen que la propaganda desarrolló en la primera mitad del mismo siglo, pues muy comúnmente se le atribuye a ella gran responsabilidad en los excesos de la Primera y Segunda guerras mundiales, la política soviética y más tarde en la paranoia de la guerra fría.

Así, esta naciente industria de la persuasión con fines comerciales pronto empezó a catalogarse como publicitaria y no como propagandística $\mathrm{y}$, a pesar de muchas veces utilizar las mismas técnicas, inició una separación práctica y teórica de sus quehaceres. A este propósito, autores 
como Jorge Molina $(2007,410)$, publicistas de profesión, enfatizan las diferencias entre propaganda y publicidad, y limitan a esta última como una actividad con exclusivos intereses económicos y no políticos ni religiosos.

Resulta entonces claro que si bien las dos actividades comparten metodologías, técnicas, leyes, referentes teóricos, etc., se evidencia un interés en separarlas. Esta motivación no se circunscribe únicamente a promover una riqueza del lenguaje y a brindar una mayor claridad en las actividades, sino a un interés que puede considerarse político, en la medida que demuestra la necesidad de una industria naciente de mostrarse precisamente apolítica.

\section{Propaganda política, militar y guerra psicológica}

Oliver Thomson (1977) en su obra Mass Persuasion in History establece ciertas categorías de la propaganda de acuerdo con sus objetivos, es decir, de acuerdo con las metas que persigue. Dichas clasificaciones son: económica, ideológica, cultural, escapista, didáctica, diplomática y, finalmente, la política y militar.

De acuerdo con esta categorización, la propaganda política se definiría como aquellos mensajes persuasivos que efectivamente tienen un objetivo político, es decir, aquellos que están relacionados directamente con el poder. Así, dentro de la propaganda política pueden encontrarse los mensajes que ciertos grupos o individuos emiten con la intención deliberada de obtener el apoyo necesario para, en primera instancia, alcanzar el poder y luego, mantenerlo.

La propaganda militar, que también es conocida como propaganda de guerra, es definida por Alejandro Pizarroso (Contreras et al., 2004, 22), simplemente como la aplicación de los modelos, formas y técnicas de la propaganda en general, pero en tiempo de guerra y para fines bélicos.
Cabe señalar que si desde esta perspectiva se indica que la propaganda militar es igual a los otros tipos de propaganda y solo se diferencia por sus objetivos y el contexto donde esta se desarrolla, entonces habría que decir muy poco de esta. Sin embargo, el mismo Pizarroso y otros autores como Luis Alberto Villamarín (2003) ponen este tipo de propaganda junto al concepto conocido como Guerra psicológica y que los anglosajones denominan Psychological Warfare.

Esta se entiende como el uso planificado de la propaganda y otras acciones orientadas a generar opiniones, emociones, actitudes y comportamientos en grupos extranjeros, enemigos, neutrales y amigos, de tal modo que apoyen el cumplimiento de fines y objetivos nacionales. Asimismo, Villamarín la define como el arte operacional militar adoptado con el fin de destruir la voluntad enemiga para combatir...; al largo plazo, toda campaña de este tipo pretende crear estados de desasosiego, frustración, insatisfacción y revuelta.

Ahora bien, si se tiene en cuenta que la guerra psicológica se desarrolla en el contexto bélico, donde el recurso principal es la violencia, entonces estas otras acciones que complementan la propaganda pueden ser también de carácter violento. Así, se entiende por qué Villamarín incluye dentro de estas acciones de guerra psicológica por ejemplo, las campañas de bombardeo aéreo durante la Segunda Guerra Mundial, que a la par de buscar alcanzar objetivos estratégicos, pretendía aterrorizar a la población civil para que esta presionara la rendición de sus Estados.

De acuerdo con lo anteriormente expuesto, es necesario enfatizar que la guerra psicológica también puede considerarse como esta disciplina donde la persuasión y la coerción se encuentran e inclusive se confunden, y parafraseando a Clau sewitz, se desarrolla con el ánimo de obligar al adversario a acatar "nuestra voluntad". Es decir, se lleva a cabo combinando actividades persuasivas no violentas y acciones claramente violentas al mismo tiempo. 
Apegándonos a esta definición, es fácil encontrar ejemplos de esta actividad en tiempos premodernos como la Edad Media o la Antigüedad. Sin embargo, debido a que el ejercicio de la violencia en los conflictos bélicos solo se regularizó y estandarizó en la Modernidad, en los ejemplos previos a esta época es bastante difícil y a veces imposible encontrar una línea de separación clara entre acciones de guerra psicológica y acciones violentas de alto impacto emocional para las víctimas y sus aliados. Así, es común encontrar en la Edad Media actos de insólita violencia y brutalidad pública como la decapitación de prisioneros, empalamientos o mutilaciones, que efectivamente en muchos casos contribuían a la desmoralización e intimidación de algún bando; sin embargo, muchos de estos actos eran provocados por la frustración e intransigencia de los actores del conflicto y no por un interés claro en destruir la voluntad de lucha del oponente (Keen, 2005).

Con la llegada de la Modernidad y la profesionalización de los ejércitos nacionales, las operaciones psicológicas también han tendido a reestructurarse y han alcanzado importantes niveles de sofisticación y efectividad. Así, es posible apreciar cómo el Ejército de Estados Unidos tras sus aprendizajes en la guerra de Vietnam, ha aumentado la relevancia de su componente de operaciones psicológicas o manejo de la información, hasta lograr importantes resultados en los últimos conflictos bélicos de carácter regular donde ha participado. Así, en la invasión a Irak ocurrida en 2003, se tienen reportes de que 9 de cada 10 soldados iraquíes se rindieron ante las tropas norteamericanas, gracias a la intensa campaña de guerra psicológica que incluía la eliminación de las comunicaciones iraquíes, el lanzamiento de piezas impresas y las transmisiones que se hacían desde vehículos HMMWV en el frente de batalla, los cuales incentivaban a las tropas iraquíes a rendirse y conservar así sus vidas. (Curtis, 2007)

\section{Guerra contra el terror}

Pizarroso $(2004,44)$ afirma: "El terrorismo, es desde sus formas más primitivas en la historia, un medio de comunicación. Es decir, el acto violento de cualquier tipo que realiza una organización terrorista está destinado a generar miedo, a manipular a un público psicológicamente". Asimismo, Pizarroso afirma que el terrorismo tiene siempre una raíz política (revolucionaria, nacionalista, religiosa, etc.); negarlo es la peor manera de abordar el problema.

Es decir, se entiende el terrorismo como un acto que carece de sentido si no se hace público y si no llega hoy día a los medios de comunicación, puesto que si dicho acto violento se hace en secreto, entonces se ha fracasado en comunicar el mensaje, cualquiera que este sea. En este sentido, es necesario reconocer que el terrorismo no es un invento contemporáneo y también pueden encontrarse ejemplos de este en la Edad Media. Quiere decir esto que si bien es una actividad bastante antigua, solo se ha empezado a teorizar en épocas recientes y especialmente desde la Revolución francesa donde aparece específicamente la palabra terrorismo para describir el uso sistemático del terror para coaccionar sociedades o Estados.

Desde esta perspectiva, los atentados del 11 de septiembre de 2001 son catalogados categóricamente como actos terroristas que incluso algunos han decidido calificar como hiperterroristas (Heinsbourg 2002), debido no solo a la magnitud de los atentados, y al elevado número de víctimas sino principalmente al impacto mediático que este ha causado y a la cantidad de personas a las que ha llegado el mensaje.

Nueve días después de los ataques, el entonces presidente de los Estados Unidos George W. Bush pronunció un discurso ante las dos cámaras del congreso de ese país. Dicho discurso revelaría las intenciones estratégicas de los Estados Unidos 
en los próximos años y determinaría los cambios en la política exterior estadounidense y su influencia en el contexto político internacional.

Autores como Bahaa-eddin M. Mazid en su investigación Presuppositions and strategic functions in Bush's 20/9/2001 speech (2007), publicada por UAE University, planteó que este discurso contenía importantes dispositivos de propaganda, que han sido utilizados por el gobierno norteamericano desde esa fecha hasta hoy en día, para lograr el apoyo del pueblo norteamericano en torno al gobierno y sus directrices, así como para justificar un proceso de expansión de poder estatal de los Estados Unidos.

Varios autores, entre los que se encuentra Pizarroso (2004), no dudan en afirmar que este discurso y finalmente casi la totalidad de la comunicación política del gobierno norteamericano evidenciaban que tras los ataques, Estados Unidos había recuperado una amenaza y un enemigo del cual carecía tras la caída del muro de Berlín. Esto se debía a que los carteles de la droga que fueron presentados como enemigos públicos en los años noventa no representaban un peligro real y visible que pudiera unir a la población norteamericana bajo un proyecto estatal de gran envergadura. La "amenaza terrorista” le permitió al gobierno de Estados Unidos aumentar su déficit y así su presupuesto en defensa, establecer una lista de enemigos entre los cuales se contaban tres Estados que fueron rápidamente catalogados como parias e integrantes de lo que se denominó el Eje del Mal, y posteriormente establecer una serie de alianzas y apoyos para sus aventuras militares en lugares de gran importancia geoestratégica.

Aunque si bien algunos gobiernos tomaron cierta distancia en torno a la invasión a Afganistán y más tarde a Irak, el apoyo que recibieron los Estados Unidos tras los ataques fue bastante decidido y notorio, donde países que anteriormente se catalogaron enemigos o por lo menos mantuvieron relaciones tensas con este, pronto pasaron a apoyarlo, como en el caso de las federaciones rusa y china.

Si bien pareciera que la espectacularidad de los ataques generó una fuerte emotividad que se concretó en el apoyo casi unánime de la opinión pública internacional hacia el pueblo norteamericano, el apoyo de estos dos países en realidad obedecía a fríos cálculos políticos. Así, para la Federación Rusa, sumarse a lo que se denominó la guerra contra el terror, le permitió en parte, legitimar sus acciones contra los separatistas chechenios, a quienes rápidamente pasó a calificar de terroristas, una movida política muy similar a la desarrollada por China al calificar a los grupos islamistas de la provincia de Xinjiang de la misma manera.

Al respecto conviene decir que analistas como Román Ortiz reconocen que en la lucha contra el terror, instituciones como las agencias de inteligencia, de cooperación internacional y de policía son mucho más efectivas que los ejércitos regulares o profesionales, puesto que los actores no se comportan siguiendo los patrones de un ejército entrenado para conflictos bélicos convencionales. No obstante, la expresión "Guerra contra el Terror" cumple una importante función propagandística (Mazid, 2007) y, como se mencionó antes, permite justificar en el discurso acciones bélicas convencionales y no convencionales. Inclusive sobre este argumento se basa la justificación al concepto de guerra preventiva, tan discutido hoy día en el contexto internacional.

Así, tras la invasión a Afganistán e Irak, los combatientes que se enfrentaron a las fuerzas militares de los Estados Unidos, que si bien siguiendo a diversos autores o doctrinas podrían ser calificados como soldados, combatientes, miembros de la resistencia, etc., pronto fueron catalogados como terroristas, siguiendo los patrones anteriormente mencionados. 


\section{La Seguridad Democrática}

Uno de los más grandes paradigmas del conflicto armado en Colombia es que el Estado colombiano ha invertido astronómicos recursos en la guerra y que a pesar de eso no ha podido alcanzar la paz. Eso se debe básicamente a que la violencia solo genera más violencia y, por tanto, Colombia está condenada no solo a una existencia violenta, sino al subdesarrollo y la pobreza.

Sin embargo, autores como Alfredo Rangel (1999) y Ricardo Esquivel (2001) han demostrado que esta afirmación es totalmente incorrecta y que, por el contrario, el gasto que ha hecho el Estado colombiano en defensa ha sido históricamente bajo en comparación con otros países de América Latina e inclusive del hemisferio occidental. De esta manera, Rangel (1999, 165) plantea que durante los años noventa, cuando el conflicto armado escaló a niveles altamente visibles, el Estado colombiano invertía menos del 1,6\% del PIB y lo aumentó a 2,4\%.

Por otra parte, Esquivel (2001, 169) desarrolló un análisis comparativo para la misma década, donde confronta la calidad técnica, la actualización de equipos y la cantidad y calidad de efectivos militares de los países latinoamericanos y este arroja como resultado, que Colombia, en lo militar, solo se encontraba por encima de países como Nicaragua, Ecuador y Panamá. Ahora bien, hay que destacar que Nicaragua tenía un producto interno bruto muy inferior al de Colombia, Ecuador posee un territorio muy pequeño y una cantidad de población mucho menor a la colombiana y Panamá había desmotado su ejército tras la invasión norteamericana en 1989. Como bien puede verse, es absolutamente notorio que a pesar de lo que se dice en torno a que el Estado colombiano invertía gran parte de su riqueza en el conflicto, esta afirmación realmente carece de fundamento.

Los anteriores argumentos son totalmente consecuentes con la posición académica que dicta que los colombianos no son violentos por naturaleza (Deas, 1999), sino que al contrario, el Estado colombiano ha sido históricamente débil y se ha mostrado incapaz de pacificar a su población a través de la imposición del monopolio de la violencia legítima. Incapacidad que ha sido aprovechada por otros actores con el fin de disputar el uso de la violencia para sus propios fines (Patiño, 2010).

Sobre esta posición básica se ha sustentado la política de Seguridad Democrática, donde se cataloga al Estado no como una institución ilegítima para gobernar a los colombianos, sino, simplemente incapaz de establecer su noción de orden. Así, Álvaro Uribe Vélez, inicialmente candidato y más tarde presidente de la República, planteó una visión de fortalecimiento del Estado y derrota política y militar a los actores armados, especialmente a las FARC.

Según Francisco Leal Buitrago (2006, 3), la política de Seguridad Democrática empezó a esbozar tres líneas de acción estratégica en los primeros seis meses de gobierno del presidente Álvaro Uribe Vélez. En primer lugar, se pretendía desarrollar una negociación de paz con los grupos paramilitares conocidos como las Autodefensas Unidas de Colombia, AUC. Dicha iniciativa obedecía básicamente a que esta organización carecía de coherencia política, un adecuado sistema de comando y control nacional, espíritu de cuerpo de los integrantes, un aceptable nivel de adoctrinamiento y, además, paulatinamente casi la totalidad de sus estructuras se encontraban fortaleciendo sus nexos con el narcotráfico.

Esta situación lentamente desembocaba en que las AUC se encontraban en un proceso de atomización donde algunas de sus estructuras inclusive habían pactado procesos de alto al fuego con las FARC y el ELN en algunos sitios del país, con el ánimo de no entorpecer sus negocios ilícitos, lo que dejaba abierta la puerta al escenario estratégico donde en pocos años algunas de estas 
estructuras serían absorbidas por los grupos insurgentes a los que años antes habían combatido.

La segunda línea estratégica de la Seguridad Democrática giraba en torno a la continuación de la lucha frontal contra las FARC, después del fortalecimiento que las Fuerzas Militares habían hecho mientras se llevaba a cabo el proceso de negociación del Caguán. Finalmente, la tercera línea estratégica giraba en torno al desarrollo de una serie de políticas puntuales que pueden entenderse como el fortalecimiento del Estado, como son la transformación de soldados campesinos en soldados regulares, conocido como "soldados de mi pueblo", el estímulo constante a los planes para fomentar la deserción en los grupos guerrilleros y la creación de redes de informantes. Sin embargo, Francisco Leal Buitrago reconoce que en esos primeros meses aún no se podía percibir una articulación consistente entre todas estas políticas y ello solo se conoció a mediados de 2003.

Por otra parte, Thomas Marks $(2005,77)$ plantea que en realidad el plan de acción del gobierno de Álvaro Uribe se basó en tres preceptos básicos: "La falta de seguridad personal es la fuente de los problemas sociales, económicos y políticos de Colombia. Esa falta de seguridad nace de la ausencia del Estado en grandes extensiones del territorio nacional. Por tanto, todos los elementos del poder nacional deben ser direccionados para ponerle fin a esta falta de integración nacional ".

Según este autor, el plan de acción se concretaba en tres pasos. En primera instancia consistió en controlar las áreas de importancia estratégica por medio de una recuperación gradual de la presencia estatal. El segundo paso consistió en el establecimiento de fuerzas de policía y ejército que de una manera permanente acompañaran y protegieran a la población civil, las que luego permitirían el afianzamiento de organismos de investigación criminal y de control del Estado en la zona. Finalmente, después de garantizarse las condiciones de seguridad en estas zonas del país, se iniciaría un plan de consolidación territorial que garantizaría el control del territorio, el funcionamiento de la justicia, la democracia local y el establecimiento y ampliación de las obras de infraestructura.

Así, el Estado colombiano fue fortaleciendo su componente coercitivo hasta cambiar la tendencia histórica de abandono de las poblaciones rurales, que según Rangel, rondaba en un 95\% en corregimientos y un $10 \%$ en municipios durante los años noventa, puesto que carecían de cualquier elemento de la fuerza pública. De igual modo, las Fuerzas Militares y especialmente el Ejército continuaron los procesos de fortalecimiento y modernización que habían iniciado con la reforma militar liderada por el entonces presidente Andrés Pastrana Arango, lo que permitió combatir y más tarde debilitar paulatinamente a las FARC.

\section{La comunicación como elemento clave del conflicto}

Es común escuchar que el Ejército de Colombia nació con la independencia misma y tuvo sus primeras pruebas triunfales en dichas guerras. Inclusive, los mitos fundacionales de la nación y del Estado colombiano están ligados a la aparición de este ejército de carácter nacional. Sin embargo, cuando se mira con detenimiento el proceso de independencia es necesario reconocer que el Ejército Libertador fue en realidad un ejército de carácter supranacional y sus principales líderes eran oriundos de poblaciones que están ubicadas en lo que es hoy el territorio venezolano.

Esta particularidad tiene sus orígenes en que Caracas era un importante puerto comercial que en épocas de la colonia mantenía una milicia ciudadana permanente y bien entrenada para enfrentarse a las incursiones de las tropas británicas o de sus corsarios. Mientras por otro lado, la capital virreinal de la Nueva Granada y las diferentes regiones de lo que hoy es Colombia (a excepción 
de Cartagena), nunca desarrollaron eficazmente estas milicias. Por tanto, en la creación de los ejércitos libertadores, fueron los venezolanos quienes principalmente ocuparon las posiciones de liderazgo militar, mientras los neogranadinos ocuparon posiciones administrativas.

En este sentido, es fácil entender por qué se concibe a Simón Bolívar como un héroe guerrero y a Santander como un personaje administrativo ligado a las leyes. Igualmente, esta situación explica en gran parte, por qué el estamento militar nunca gozó en Colombia de una posición política importante, a diferencia de países como Venezuela, Chile o Argentina, lo que desembocó en que en Colombia las dictaduras militares brillan por su ausencia y solo se concretaron con el apoyo de los partidos políticos tradicionales como es el caso del general Rojas Pinilla a mediados del siglo XX.

Esta situación sumada a otros factores como el establecimiento del Frente Nacional, la ausencia de un servicio militar obligatorio para todas las clases, la aplicación de técnicas de guerra insurgente en el contexto de la guerra fría, etc., desembocó en que hacia finales del siglo XX, el Ejército de Colombia se veía como una institución lejana a la población civil. Además, de poco eficiente, un tanto corrupta, violadora de derechos humanos, pero especialmente débil y poco profesional. Las derrotas militares de los años noventa y la fuerte campaña de propaganda que desarrollaron las FARC en esa década simplemente agudizaron esta percepción.

Con la Reforma Militar iniciada por el presidente Andrés Pastrana, el componente de comunicaciones del Ejército pasó a ser parte fundamental del fortalecimiento de esta fuerza (Patiño, Vargas, 2006). Aquí, es necesario aclarar que esta afirmación no solo se convirtió en retórica como en años pasados, sino que se hizo evidente en los resultados y en la estructura misma del Ejército. Es decir, desde mediados del siglo XX el componente de comunicaciones era teóricamente parte impor- tante del Ejército, hasta tal punto que todas las unidades superiores a tipo Batallón tenían un departamento encargado de orientar esta actividad.

Inclusive, en Bogotá existía desde los años noventa una escuela de formación que inicialmente se llamó Escuela de Operaciones Psicológicas, pero que fue rápidamente rebautizada como Escuela de Relaciones Civiles y Militares. Dicha escuela capacitaba a sus alumnos, (todos, personal de las Fuerzas Militares, especialmente del Ejército) en técnicas de propaganda y guerra psicológica.

No obstante, hay que reconocer que estas actividades no eran prioritarias para el Comando del Ejército ni para el Comando General de las Fuerzas Militares, motivo por el cual es fácil entender por qué no era posible encontrar a inicios de los años noventa unos lineamientos generales de carácter nacional para el manejo de la información que producía la fuerza pública. En la práctica, cada unidad táctica tenía plena libertad para realizar las acciones que considerara necesarias, las cuales eran dirigidas y llevadas a cabo por personal que no tenía la suficiente capacitación ni experiencia en el manejo de información y comunicación, debido a que eran oficiales o suboficiales de carrera sin ninguna formación técnica o profesional en el área de la comunicación social, publicidad, diseño o similares y en el mejor de los casos con una breve capacitación en esta escuela. Además, estos departamentos por lo general no desarrollaban verdaderamente operaciones psicológicas o de propaganda, sino que eran encargados de mantener una buena relación con los mandatarios locales, funcionarios públicos y un número limitado de ciudadanos del común.

A diferencia de eso, con la Reforma Militar, el componente de comunicaciones pasó a ser parte fundamental de la estrategia contra insurgente y dejó de ser visto como un elemento asilado o, en el mejor de los casos, complementario. Al respecto, conviene decir que hubo profundos 
cambios en la organización misma del Ejército y el componente de comunicaciones pasó a depender directamente de quienes en la Fuerza planeaban y dirigían las operaciones bélicas en el país, es decir, la Jefatura de Operaciones. (Fundación Seguridad y Democracia, 2003:60). Así, empezó a conocerse la actividad de las comunicaciones como "Acción Integral " donde ya no se tendría como responsabilidad principal limitarse a mantener una buena imagen del Ejército, sino a desarrollar activamente operaciones de guerra psicológica tendentes a debilitar la voluntad de lucha del enemigo y aumentar el apoyo que la población civil brindara al Estado y su fuerza pública.

En concordancia con esto y con la "Guía de Planeamiento Estratégico-Objetivos, políticas y estrategias, del Ministerio de Defensa“ (1997:28), puede apreciarse cómo la Acción Integral trabaja sobre dos niveles: el táctico y el estratégico. En el primero se desarrollaron acciones de este tipo en las áreas donde operan los grupos armados ilegales, con el fin de debilitar su voluntad de lucha, lograr el apoyo de la población civil y finalmente mantener a las propias tropas altamente motivadas. Por otra parte en el nivel estratégico, se dirigió y gestionó la transmisión de la información producida por las fuerza y por el conflicto mismo a la opinión pública, con el objetivo de obtener su apoyo hacia la gestión de la fuerza pública. Todo esto se realizó con el fin de crear un marco de información que beneficiara la imagen del Estado y de sus acciones y al mismo tiempo que debilitara la imagen que los diferentes públicos tenían sobre los grupos armados ilegales y la imagen que estos tienen sobre sí mismos.

Así, la campaña La desmovilización es la salida fue dirigida al nivel táctico, con el fin de debilitar la voluntad de lucha de los combatientes guerrilleros, y campañas como Los héroes en Colombia sí existen y Vive Colombia, viaja por ella estaban dirigidas al nivel estratégico con el fin de aumentar en la opinión pública la percepción de estar protegidos por un ejército de alta calidad y gozar de buenas condiciones de seguridad que ya le permitían a la población civil desplazarse con seguridad por el territorio nacional.

Al profundizar sobre el primer nivel, es posible apreciar que la campaña La desmovilización es la salida tiene sus orígenes en 2006, la cual se dio a conocer a través de una serie de spots televisivos creados por la agencia de publicidad Lowe SSP3 (Went, 2009). El equipo creativo de esta agencia dirigida por José Miguel Sokoloff fue contratado por el Ministerio de Defensa de Colombia, con el fin de crear mensajes persuasivos que motivaran a los guerrilleros rasos a abandonar la lucha guerrillera.

Después de una investigación que incluía entrevistas con guerrilleros desmovilizados, se descubrieron insights publicitarios de los guerrilleros rasos, razón por la cual se crearon una serie de historias que no se basaban en asuntos abstractos de la lucha guerrillera, generalidades de un grupo como las FARC o clichés de carácter moral, sino principalmente sobre las frustraciones que afectan directamente a los combatientes de los grupos armados al margen de la ley. Así cada subversivo que fuera expuesto a los mensajes se sentiría identificado con las situaciones allí desarrolladas, tales como tener que asesinar a un compañero acusado injustamente de traición, a la mujer combatiente que era obligada a abortar, es decir, enfrentarse a una dura realidad donde se veía obligado a realizar acciones que consideraba injustas para sí mismo.

Así, el 12 de noviembre de ese año se empezaron a emitir una serie de comerciales de televisión que fueron complementados por cuñas de radio y piezas publicitarias distribuidas en regiones donde operaban estos grupos guerrilleros. Dichas piezas buscaban impactar fuertemente en el público objetivo manteniendo altos niveles de emotividad y a través de medios de comunicación no convencionales conocidos como BTL. De esta manera, en 2010 por encargo del Ejército, la agencia de publicidad DDB Colombia, desarrolló una idea que 
consistía en arrojar desde helicópteros, miles de chupos para bebés, los cuales iban acompañados de un fuerte texto: "Si usted hace parte de un grupo ilegal, su hijo no nacerá para gozar de algo tan simple como esto" (Proyecto diseño,2010).

Además, otro tipo de acciones similares consistían en arrojar balones de fútbol en medio de la selva con mensajes que hacían alusión a que en la lucha armada era imposible jugar un partido de fútbol con tranquilidad. También se recurrió a la decoración de árboles con luces y adornos navideños en medio de las zonas de conflicto, especialmente en el área donde se consolidaba el Plan Patriota. Esta iluminación navideña se encendía automáticamente y estaba acompañada de mensajes que invitaban a los combatientes guerrilleros a desmovilizarse y disfrutar de una Navidad en casa al lado de sus familias.

Es innegable que este esfuerzo resultó un éxito rotundo, puesto que según los registros cerca de 11.405 insurgentes dejaron voluntariamente las armas entre los años 2002 y 2008 (Went, 2009). Sin embargo, hay que destacar que dichas desmovilizaciones no se debieron únicamente a la emisión de estos mensajes, sino a la sinergia que se produjo entre el manejo de la información y las constantes operaciones ofensivas desarrolladas en diferentes zonas del país, las cuales también incluían recompensas por información y un notable avance en la inteligencia técnica y humana aplicada en el área de operaciones, las cuales rindieron notables frutos operativos. Esta situación aumentó el nivel de éxito de las operaciones militares en el país y paralelamente creó un sentimiento de paranoia en los altos y medios mandos de las FARC, quienes creían que su movimiento había sido ampliamente infiltrado por la fuerza pública, lo que se tradujo en un aumento de ejecuciones sumarias de aquellos combatientes que eran sospechosos de ser infiltrados (Semana, 2010), lo que paradójicamente fortaleció el mensaje emitido en los comerciales de la campaña de desmovilización.
De acuerdo con lo anterior, es entendible la situación que se presentó con la insurgente conocida como "Karina", quien a lo largo de los años escaló posiciones de liderazgo en las FARC hasta llegar a convertirse en jefe de frente, pero después de sufrir una fuerte presión militar terminó sumándose al plan de desmovilización y participando en la campaña propagandística ${ }^{2}$. Aunque si bien, "Karina" alguna vez fue calificada por las Fuerzas Militares como una de las guerrilleras más sanguinarias del país, eso no fue impedimento para que se sumara a la campaña de Acción Integral.

Desde el punto de vista de las operaciones psicológicas, incluirla en las acciones propagandísticas a través de comerciales y cuñas radiales, promoviendo la desmovilización produciría más resultados operacionales que simplemente aislarla de los medios de comunicación. Es decir, debido a su reconocimiento dentro de las filas de la subversión, su participación en la campaña produciría más deserciones y por tanto sacaría del conflicto a más alzados en armas. Este es un simple cálculo político que en la relación costo beneficio supera los argumentos de aquellos que afirman que es completamente injusto que "Karina" reciba los beneficios del Plan de desmovilización simplemente por participar en la campaña ${ }^{3}$.

Puede decirse que esta campaña tuvo un gran impacto en la opinión pública nacional debido a la gran emotividad de los mensajes, el free press que recibió, pero especialmente porque los comerciales de televisión fueron pautados principalmente en las transmisiones de partidos de fútbol que hacían los canales nacionales. En este punto es de destacar que no se tomó la decisión de pautar allí debido al alto raiting, sino a que la investiga-

2 Si bien este comercial de televisión se pautó en los principales canales colombianos, luego fue subido a la red Youtube y está disponible en: http://www.youtube.com/ watch?v=w24S _ a5J1U

3 Sobre este dilema puede hacerse reflexión apoyándose en Rafael Del Águila y su libro: La senda del Mal, política y razón de Estado. 
ción realizada por Lowe SSP3 arrojó resultados concretos que señalan que dichas transmisiones eran vistas ávidamente por los guerrilleros rasos quienes eran el público objetivo de la campaña (Went, 2009).

Es necesario aclarar que la opinión pública no era el público objetivo de estos mensajes, pero al ser expuesta indirectamente a estos, la campaña ganó gran popularidad, y se sumó a los otros esfuerzos propagandísticos que el Estado realiza aún hoy día para mejorar su imagen y especialmente para obtener el apoyo de la ciudadanía en la lucha contra insurgente.

Por otra parte, cuando se profundiza sobre el enfoque estratégico, es decir, aquel dirigido a la opinión pública, es posible apreciar que la campaña Vive Colombia, viaja por ella obedecía a un interés muy claro donde lo que se buscaba era incentivar a que los colombianos viajaran a diferentes regiones del país, especialmente por vía terrestre. Aunque aparentemente dicha iniciativa buscaba promover el turismo y, por tanto, tendría un interés económico de por medio, en realidad, también tenía un poderoso mensaje que giraba en torno al conflicto armado en Colombia y era que con la Seguridad Democrática y a diferencia de años anteriores, los viajes por vía terrestre ya eran posibles.

Es comprensible que el gobierno nacional haya decidido impulsar esta iniciativa puesto que se complementaba fuertemente con otras acciones como por ejemplo las caravanas turísticas y el Plan Meteoro, el cual consistía en la protección de los principales corredores viales del país principalmente a manos de fuerzas de caballería mecanizada, tropas regulares del ejército y fuerzas de policía. Resulta evidente que la presencia de estas fuerzas en este contexto no buscaba únicamente asegurar las vías, sino transmitir una sensación de seguridad a todos los viajeros y más tarde a través de voz a voz y el free press a toda la opinión pública.
Además, la campaña Los héroes en Colombia sí existen buscaba cambiar la imagen negativa o en el mejor de los casos la pobre imagen que ha tenido el Ejército de Colombia desde sus orígenes. Así, se pretendía eliminar cualquier connotación negativa o diminutiva del personal de las Fuerzas Militares, especialmente del Ejército y mostrarlos como personas de cualidades excepcionales que están dispuestos a altos niveles de sacrificio en aras de proteger al ciudadano del común.

Esta campaña que se hace visible a través de spots de televisión desde 2007 (Ejército Nacional, 2010) recurre a la presentación de historias donde principalmente se narran las acciones cotidianas que realizan los miembros de la fuerza pública y los riegos a los que se someten a diario. Al mismo tiempo, se muestra al Ejército como una institu ción con un nivel de superioridad tecnológica, compromiso y profesionalismo sin igual.

Hay que señalar en este punto, que al apreciar los mensajes anteriormente descritos, es relativamente fácil vislumbrar la intención del Ministerio de Defensa, pues esta es explícita y no da lugar a dudas acerca de los objetivos ni de los medios utilizados. No obstante, estas acciones hacen parte de un entramado mucho más elaborado y que se desarrolla con más eficacia desde finales de los años noventa. Al respecto conviene decir que ya desde mediados de esa década, el Ministerio contaba con espacios televisivos donde eran presentados programas tales como "Comandos" y "Hombres de Honor", además que realizaban acciones puntuales con públicos específicos a través de acciones como "Soldados por un día"u "oficiales de la reserva", las cuales buscan básicamente acercar a la población civil al estamento militar (Ejército Nacional,2010).

Sin embargo, otro tipo de acciones de manejo de la información tuvieron un impacto mucho mayor en la opinión pública puesto que si bien eran más discretas, aseguraron una gran audiencia. Esto se hizo por medio del fortalecimiento de 
las oficinas de información y prensa de brigadas y divisiones del Ejército, además de la creación de agencias de noticias en el Ejército (ANE) y la Policía (ANNP), las cuales tienen como función traducir la información obtenida por las tropas y las unidades de policía en el área de operaciones, en información noticiosa la cual es suministrada a la prensa televisiva, radial y escrita. Es necesario destacar, que a diferencia del pasado, todas estas oficinas cuentan hoy día con profesionales de las áreas de la comunicación y la publicidad, los cuales siguen los lineamientos planteados por la Jefatura de Operaciones.

De esta manera la opinión pública colombiana en los últimos años ha sido expuesta a un flujo constante de noticias donde se le informa acerca de los éxitos operacionales, representados en muertes de subversivos ${ }^{4}$, incautación de material de guerra, bombardeos, capturas, desmovilizaciones, lo que ha favorecido una imagen positiva acerca de la Institución y de que la balanza del conflicto armado en Colombia está inclinándose hacia el lado del Estado. Acciones como la muerte de alias "Iván Ríos" a manos de su jefe de seguridad; el escape de Oscar Tulio Lizcano con ayuda de uno de sus captores; las muertes del "Negro Acacio", "Raúl Reyes", "El Mono Jojoy", etc.; el rescate de Ingrid Betancurt y varios militares secuestrados, se convirtieron en espectáculos televisivos difundidos con abundante material grabado y editado por las Fuerzas Armadas. Ahora bien, hay que señalar que el aumento en la efectividad de las operaciones se debe a las mejoras producidas por la Reforma Militar, pero el aumento en las noticias se debe a un real interés de la fuerza pública porque esos eventos se conviertan en noticia.

4 Quizás el afán de producir este tipo de noticias, sumado a la presión de mandos superiores y a la obsoleta estrategia del Body Count, haya influido en la aparición de los tristemente célebres "falsos positivos". Situación a todas luces reprochable, y que debe ser lamentada por todos los operadores psicológicos del Ejército, no solo por ser una violación flagrante a los derechos humanos que va en contra de la misión constitucional de las Fuerzas Armadas, sino también porque afecta enormemente la imagen de la Institución y echa a tierra gran parte de los logros obtenidos en la última década. Sin embargo, eso es tema de otro análisis y no del presentado en este artículo.
Además, los programas televisivos como "Contacto" y "Vamos Colombia", más el aumento en el número de estaciones radiales del Ejército, la Armada y la Policía, los cuales emiten mensajes positivos acerca de la fuerza, más resúmenes de noticias, han contribuido a acercar a estas instituciones a la población civil ${ }^{5}$.

Se traduce todo esto en que la imagen de las Fuerzas Militares y de Policía ha mejorado ostensiblemente y en la última década, la opinión pública ha respaldado al gobierno nacional en su estrategia por solucionar el conflicto armado en Colombia por una vía diferente a la negociación como había sido planteada por los gobiernos anteriores a 2002. Es decir, la inmensa mayoría en Colombia hoy día esperan que el Estado someta militarmente a las FARC. Resulta obligado señalar aquí, que la derrota militar no se produce cuando todos y cada uno de los miembros de las FARC hayan muerto (cosa no solo moralmente inaceptable, sino imposible de llevar a la práctica), sino cuando su voluntad de seguir luchando haya desaparecido, es decir, cuando sobre sus cálculos políticos resulte que el medio para obtener mayores beneficios sea la negociación o el sometimiento y no la lucha armada. Precisamente este concepto se incluye en las teorías de la guerra psicológica, donde el fin último es, como se mencionó anteriormente, destruir su voluntad de lucha.

Es necesario resaltar que el Estado y especialmente las Fuerzas Armadas a través de un hábil manejo de la información han creado un clima de opinión donde la opinión pública conserva la idea de que el bando vencedor hoy día es indiscutiblemente el Estado, y el sentido común nos dicta que es más provechoso apoyar al bando vencedor. Esto se ha logrado gracias a la idea que la fuerza pública es hoy más poderosa que en el pasado y las Farc cada día más débiles. La repetición a través de diversos medios ha sido clave de esto. Como bien lo señaló Jean Marie Domenach: "La

5 Para citar solo un ejemplo, según el Ministerio de Defensa, el Ejército en 2010 contaba con 30 emisoras 
persistencia del tema, junto con la variedad de su presentación, es la cualidad rectora de toda campaña de propaganda“" (Domenach, 1968:66).

Por otra parte, tras los ataques del 11 de septiembre, el gobierno nacional rápidamente comprendió que la Guerra contra el Terror promulgada por el gobierno de los Estados Unidos, se convertía en un fenómeno global. Así, las FARC rápidamente fueron catalogadas como terroristas y las anteriores menciones que se hacían para calificar a este grupo como subversivo y a sus integrantes como bandoleros, facinerosos o delincuentes, desaparecieron. Por tanto, el calificativo que imperó fue el de narcoterroristas.

Esta decisión trajo dos resultados casi inmediatos: en primera instancia las FARC perdieron gran parte de su reconocimiento que en alguna medida era reconocida en el contexto internacional, pues tras el fallido proceso de paz, iniciado con el gobierno del entonces presidente Andrés Pastrana y en un nuevo escenario geopolítico, las FARC vieron sus espacios reducidos. Y en segunda instancia, el nuevo carácter de narcoterroristas les quitó la legitimidad que en algún momento pretendieron tener al declararse defensores del "pueblo". Así, en el discurso ya no eran considerados como un movimiento insurgente o inclusive beligerante, sino todo lo contrario, su categoría fue notablemente disminuida y sus principales dirigentes pasaron a ser comparados con personajes como Osama Bin Laden.

\section{Conclusiones}

Colombia es testigo hoy día de un esfuerzo propagandístico sin precedentes en su historia, donde en el contexto nacional, claramente el Estado mantiene la iniciativa y se muestra hasta ahora como indiscutible vencedor. Atrás quedaron las imágenes televisivas producidas durante la zona de despeje, que mostraban a las FARC prácticamente como un ejército regular que dominaba amplias zonas del territorio colombiano, mientras las imágenes que predominan hoy día en los espacios televisivos son las de sus principales líderes capturados o muertos.

Desde una perspectiva geopolítica, se entiende que este esfuerzo propagandístico nace en los años noventa tras la necesidad manifiesta del Estado por eliminar las principales amenazas a su seguridad y superviviencia. La propaganda y las operaciones psicológicas resultaron ser herramientas notables para debilitar estas amenazas y lograr el apoyo de la población civil, favoreciendo la gobernabilidad. Puede decirse inclusive que la propaganda ha jugado un importante papel en los esfuerzos que han tenido los últimos gobiernos de consolidar un Estado moderno en Colombia ${ }^{6}$.

Este esfuerzo ha encontrado en los principales medios de comunicación masiva del país, sus aliados perfectos, puesto que han estado prestos a difundir los mensajes elaborados por la fuerza pública. Situación que no resulta sorprendente en un país democrático donde las élites políticas y económicas, quienes son propietarios de la totalidad de los medios masivos, en su gran mayoría apoyan al Estado y al modelo de gobierno. Esto guarda perfecta relación con el Modelo de Propaganda de Noam Chomsky (Chomsky, 1990) el cual afirma que las democracias tienen sus propios métodos de control de información y que, por tanto, se transmitirán por los medios masivos, aquellos mensajes que sean beneficiosos para el Estado y las élites que lo respaldan.

\section{Referencias bibliográficas}

Chomsky N., y Herman E., (1990) Los guardianes de la libertad: propaganda, desinformacion y consenso en los medios de comunicación de masas. España: Crítica Grijalbo.

Creveld, M. (1999). The rise and decline of the state. Cambridge: Cambridge University Press.

6 Desde la perspectiva de Max Weber e inclusive desde Thomas Hobbes y Martin Van Creveld. 
Colombia ruge en Cannes. (2010, agosto-septiembre). Revista Proyecto Diseño, 68, 12.

Curtis O., (2007 mayo-junio). Army IO is PSYOP. Influencing more with less. Military Review, 3, 67-75

Deas, M. (1999) Intercambios violentos. Bogotá: Taurus

Domenach, J. (1964) La propaganda política. Buenos Aires: Editorial Universitaria de Buenos Aires

Ejército Nacional. Los héroes en Colombia sí existen. (2010, diciembre) Disponible en: http://www.ejercito.mil. co/?idcategoria $=193294$

Ejército Nacional. Profesionales Oficiales de la Reserva. (2010,diciembre) Disponible en: http://www.ejercito. mil.co/?idcategoria $=82838$

Esquivel, R. (2001). Colombia indefensa. Bogotá: Planeta colombiana.

Fellows, E. (1959). Propaganda: "History" of a Word. American Speech. Vol 34:3, 182-189

Fundación Seguridad y Democracia. (2003). Fuerzas Militares para la guerra. La agenda pendiente de la reforma militar.

Hernández, H. Infante, R. (1991) Análisis de información internacional y medios de difusión. La Habana: Editorial Pueblo y Educación.

Keen, M. (2005). Historia de la guerra en la Edad Media. Madrid: Machado libros.

Leal, F. (2006). La política de seguridad democrática. Análisis político. No 57, 3-30.

Los fusilados de las Farc. (2010, febrero 10). Semana, $145,42-43$

Marks, T y Rangel, A. (2005). La sostenibilidad de la seguridad democrática. Bogotá: Fundación seguridad y democracia.

Mazid, B. (2007). Presuppositions and strategic functions in Bush's 20/9/2001 speech. Journal of Language and politics. 6:3, 351-375.
Ministerio de Defensa de Colombia. (1997). Guía de Planeamiento Estratégico: Objetivos, políticas y estrategias. Bogotá.

Molina, J. Morán, A. (2007) Viva la publicidad viva 3. Bogotá: Editorial Politécnico gran colombiano.

Patiño, C. Guerra y construcción del Estado en Colombia 1810-2010. Bogotá: Universidad Militar Nueva Granada.

Patiño, C. Vargas. A. (2006). Reforma militar en Colombia: contexto internacional y resultados esperados. Medellín: Editorial Universidad Pontificia Bolivariana.

Pizarro, L. E. (2004). Una democracia asediada. Colombia: Editorial norma.

Pratkanis, A. Aronson, E. (1994) La era de la propaganda. Uso y abuso de la persuasión. Barcelona: Ediciones Paidós Ibérica.

Presidencia de la República-ministerio de Defensa Nacional. (2003) Política de defensa y seguridad democrática, Bogotá, Ministerio de Defensa, 2003. Citada por Francisco Leal Buitrago. Ibid. P11

Rangel, A. (1999). Colombia: guerra en el fin de siglo. Bogotá: TM editores.

Rangel, Alfredo. (1996, noviembre). De la guerra de guerrillas a la guerra de movimientos. Estrategia económica y financiera, 248, 28-29

Thomson, O. Mass Persuasion in History: An historical analysis of the develpment of propaganda thechniques. Edimburgo: Paul Harris.

Villamarín L., (2003, septiembre-octubre) Guerra irregular y guerra de guerrillas. The Military Review, 75-81

Wentz L., (2009, noviembre). Call it guerrilla marketing: Colombia uses ads to persuade rebels to turn themselves in. Advertising Age, 39, 47-49

Young, K. (1967). La opinión pública y la propaganda. Buenos aires: Editorial Paidós 